\title{
Seborrheic Keratoses of Florid Eruption
}

\author{
Helen Gharwan Jeremy D. Gradon \\ Johns Hopkins University/Sinai Hospital of Baltimore, Department of Internal \\ Medicine, Baltimore, Md., USA
}

\section{Key Words}

Seborrheic keratosis - Colon cancer · Gastrointestinal · Skin · Pruritus · Paraneoplastic

\begin{abstract}
We report the case of a 79-year-old Caucasian man, who developed numerous pruritic seborrheic keratoses on his chest and back within one year. An underlying malignant disease was suspected. Upper and lower endoscopies were performed and the patient was diagnosed with adenocarcinoma of the ascending colon. We discuss the clinical significance of his cutaneous symptoms/signs, and review the medical literature on the paraneoplastic sign of Leser-Trélat.
\end{abstract}

\section{Introduction}

Cutaneous paraneoplastic syndromes include acanthosis nigricans, the sign of LeserTrélat, eruptive acrochordons, acquired ichthyosis, erythroderma, palmoplantar hyperkeratosis, acquired hypertrichosis lanuginosa, erythema gyratum repens, necrolytic migratory erythema, Bazex's syndrome and dermatomyositis [1]. The presence of either syndrome in patients warrants evaluation for a possible underlying malignancy. Here we report the case of a 79-year-old man, who developed numerous several centimeter-large seborrheic keratoses on his chest and back within the time period of one year. Workup led to the diagnosis of colonic adenocarcinoma, underscoring the paraneoplastic etiology of the seborrheic keratoses in this patient.

\section{Case Report}

A 79-year-old man with a previous diagnosis of chronic lymphocytic leukemia was seen for preoperative evaluation prior to elective right peripatellar bursectomy after having failed antibiotic treatment. On physical examination numerous seborrheic keratoses in a Christmas tree pattern [2] were noted on his chest and back (fig. 1). Upon questioning the patient reported that the lesions had appeared and advanced within the past twelve months on his trunk. They were occasionally itching, 
but not troubling him otherwise. He was seen by a dermatologist, who suggested performing endoscopies of the upper and lower gastrointestinal tract. Colonoscopy led to the diagnosis of adenocarcinoma of the ascending colon. The patient had not noted clinical symptoms otherwise suggestive of colon cancer, such as unintentional weight loss or recent change of bowel habits. He underwent right hemicolectomy and was referred to a medical oncologist for further management. The clinical presentation of the seborrheic keratoses in this patient was found to be consistent with the sign of Leser-Trélat.

\section{Discussion}

Leser-Trélat is a rare dermatologic finding named after two surgeons, the German Edmund Leser (1828-1916) and the French Ulysee Trélat (1827-1890) [3]. However, the first descriptions of patients with characteristic signs of Leser-Trélat were published in 1900 [4] and 1901 by the German dermatologist Eugen Holländer.

The Leser-Trélat sign is characterized by the sudden onset of multiple seborrheic keratoses or an unusually rapid increase in size and number of preexisting seborrheic keratoses, occasionally on an inflammatory base. It is commonly associated with malignancies, primarily gastrointestinal adenocarcinomas [5, 6], but also squamous cell carcinomas, leukemias and lymphomas. It has furthermore been reported in patients with sarcomas, germinomas and nasopharyngeal carcinomas. Although patients with nonmalignant conditions, such as pregnancy [7], HIV infection [8] or after having received heart transplantation [9], can also develop seborrheic keratoses of florid eruption, the term Leser-Trélat usually implies paraneoplasia.

The significance of this sign has been debated in the medical literature [10], as Leser-Trélat is observed primarily in elderly individuals, who are statistically at higher risk for developing both seborrheic keratoses as well as various malignancies.

Therefore, accurate diagnosis is linked to the rapidity of onset of seborrheic keratoses, and to the growth behavior of previously noted seborrheic keratoses. Only rarely has Leser-Trélat been reported in younger patients [11].

The seborrheic keratoses seen in Leser-Trélat differ neither morphologically nor histologically from commonly seen seborrheic keratoses. They are found predominantly on back and chest of patients, and there is no predilection for patients' gender or ethnic/ancestral background. The most prevalent clinical symptom is pruritus [12], seen in $43 \%$ of malignant cases [12,13]. In approximately $20 \%$ of cases acanthosis nigricans is also present, either at the time of cancer diagnosis or it develops subsequently [13].

While the pathogenesis of this condition is unclear and remains to be elucidated, due to the proliferative nature of cutaneous paraneoplasias, a possible pathogenic role of epidermal growth factor and alpha-transforming growth factor in the development of the seborrheic keratoses associated with malignancies has been hypothesized and reported [14].

On rare occasions, skin manifestations similar to the Leser-Trélat sign can be mimicked by malignant melanoma, thus justifying excision biopsies and histologic examinations of suspicious lesions in distinct cases [15]. 


\section{Conclusion}

Florid eruption or abnormally fast growth of seborrheic keratoses especially in elderly patients should always raise the suspicion for an underlying malignant disease, in particular for gastrointestinal adenocarcinomas. Performing an endoscopic evaluation of the gastrointestinal tract of affected patients is therefore the appropriate course of action.

\section{Disclosure Statement}

All authors have no conflict of interest.

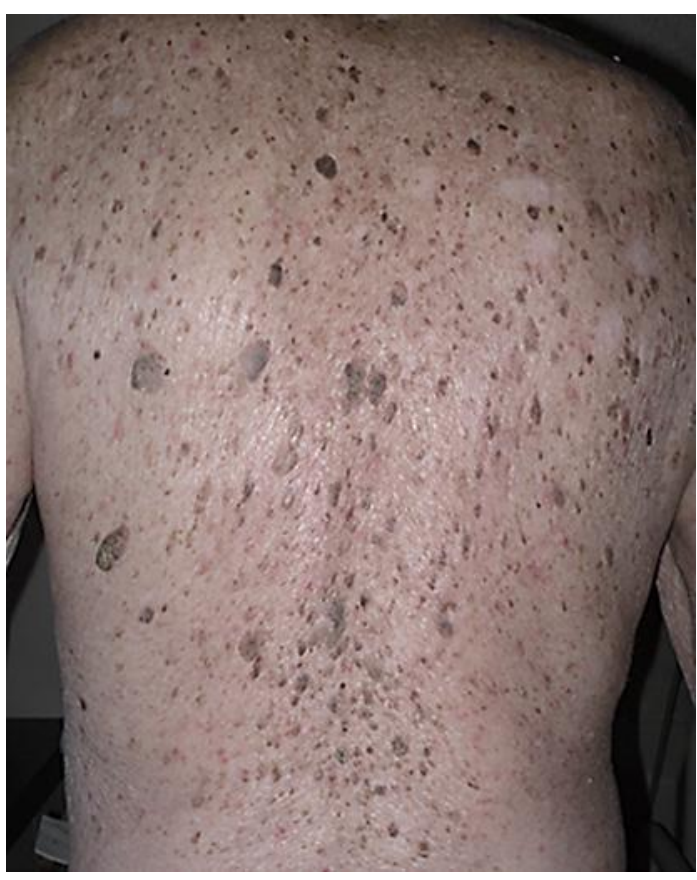

Fig. 1. Seborrheic keratoses on the patient's back. 


\section{References}

1 Ramos-E-Silva M, Carvalho JC, Carneiro SC: Cutaneous paraneoplasia. Clin Dermatol 2011;29:541-547.

2 Wollenberg A, Eames T: Skin diseases following a Christmas tree pattern. Clin Dermatol 2011;29:189194.

3 Leser E: Über ein die Krebskrankheit beim Menschen häufig begleitendes, noch wenig gekanntes Symptom. Münch Med Wochenschr 1901;51:2035-2036.

-4 Holländer E: Beiträge zur Frühdiagnose des Darmcarcinoms (Hereditätsverhältnisse und Hautveränderungen). Dtsch Med Wochenschr 1900;6:483-485.

5 Nanda A, Mamon HJ, Fuchs CS: Sign of Leser-Trélat in newly diagnosed advanced gastric adenocarcinoma. J Clin Oncol 2008;26:4992-4993.

6 Constantinou C, Dancea H, Meade P: The sign of Leser-Trelat in colorectal adenocarcinoma. Am Surg 2010;76:340-341.

7 Garcia RL, Bishop ME: The rapid onset of seborrheic keratosis of the breasts during pregnancy. J Assoc Mil Dermatol 1977;3:13-14.

-8 Inamadar AC, Palit A: Eruptive seborrhoeic keratosis in human immunodeficiency virus infection: a coincidence or 'the sign of Leser-Trélat'? Br J Dermatol 2003;149:435-436.

$\checkmark 9$ Hsu C, Abraham S, Campanelli A, et al: Sign of Leser-Trélat in a heart transplant recipient. Br J Dermatol 2005; 153:861-862.

10 Rampen HJ, Schwengle LE: The sign of Leser-Trélat: does it exist? J Am Acad Dermatol 1989;21:50-55.

11 Westrom DR, Berger TG: The sign of Leser-Trélat in a young man. Arch Dermatol 1986;122:1356-1357.

12 Holdiness MR: Pruritus and the Leser-Trélat sign. J Am Acad Dermatol 1988;18:149.

13 Holdiness MR: The sign of Leser-Trélat. Int J Dermatol 1986;25:564-572.

14 Ellis DL, Kafka SP, Chow JC, et al: Melanoma, growth factors, acanthosis nigricans, the sign of LeserTrelat, and multiple acrochordons: a possible role for alpha-transforming growth factor in cutaneous paraneoplastic syndromes. N Eng J Med 1987;317:1582-1587.

15 Rubegni P, Mandato F, Mourmouras V, et al: False Leser-Trélat sign. Int J Dermatol 2009;48:912-913. 